\title{
THE POLITICAL ECONOMY OF INTERNATIONAL REGULATORY CONVERGENCE IN PUBLIC UTILITIES
}

\author{
Jean-Philippe Bonardi \\ University of Lausanne - Faculty of Business and Economics \\ Lausanne, Dorigny - 1015 - Switzerland \\ Tel: 0041. 692 3440, Email: Jean-Philippe.Bonardi@unil.ch \\ Santiago Urbiztondo \\ Fundación de Investigaciones Económicas Latinoamericanas (FIEL), \\ Buenos Aires, Argentina
}

Tel: 54114314 1990, Fax: 54114314 8648, Email: $\underline{\text { santiago@ fiel.org.ar }}$

and

Bertrand Quélin

HEC Paris, Member of the CNRS Research Group GREGHEC (UMR \#2959)

1, rue de la Liberation - 78351 Jouy en Josas Cedex, France

Tel: +3313967 72 70, Fax: +331396770 84, Email: quelin@hec.fr

July $2008^{*}$

Paper submitted to the International Journal of Management and Network

Economics (IJMNE)

\begin{abstract}
To what extent should public utilities regulation be expected to converge across countries? When it occurs, will regulatory convergence lead to positive outcomes for utility sectors? This paper attempts to provide new answers to these questions. Building on the core proposition of the New Institutional Economics (NIE) that similar regulations generate different outcomes depending on their fit with the underlying domestic institutions, we develop a simple theoretical model and explore its implications by examining the diffusion of local loop unbundling (LLU) regulations in the telecommunications sector. We find support for the ideas (1) that once institutional factors are taken into account, one should expect some convergence in public utility regulation but with still a significant degree of local experimentation, and (2) this process will lead to very different results regarding the impact of regulation.
\end{abstract}

\section{JEL: L5; K2; F42}

\footnotetext{
* The authors are grateful for the comments of A. Chambouleyron, W. Cont and the participants at the 18th European Regional ITS (International Telecommunications Society) Conference (Istanbul, Turkey, 2007), and the EPFL Brown bag seminar on Network Industries. The authors thank France Telecom for granting this research project.
} 


\section{THE POLITICAL ECONOMY OF INTERNATIONAL REGULATORY CONVERGENCE IN PUBLIC UTILITIES}

\section{Introduction}

Over the last twenty-five years, globalisation has accompanied -and has probably been fosteredby what many see as a strong convergence in regulatory policies, especially regarding the reform of public utility sectors, ${ }^{1}$ such as telecommunications, electricity and water (Eising, 2002; Genoud and Finger, 2002; Henisz et al., 2005). ${ }^{2}$ Convergence across countries in the way these sectors -and many others- are organized is widely believed to be the result of several factors, such as competition, learning and capital mobility (Bennett, 1991; Berger and Dore, 1996). Over time, and after specific historical legacies disappear, common economic and public policy structures emerge, generating regulatory convergence.

Critical in this view is the idea that some best practices regarding the way public utilities should be regulated tend to emerge through the experiences of certain countries, and these best practices are then imitated by others (Gertler, 2001). Regulatory convergence occurs as a consequence of this virtuous process, not only regarding the regulations that are adopted but also regarding common results of these regulations: 'imitators' are assumed to catch up with 'leaders', i.e., the countries that have been the first to develop and implement the best practices.

In the context of telecommunications, which we will use here to illustrate our broader theoretical approach, policies that have been considered as best practices were, in the beginning, general guidelines, such as privatisation of state-owned enterprises, creation of independent regulatory bodies and competitive entry into long-distance, local and international call markets. More specific ideas have emerged recently in an attempt to fully benefit from the possibilities generated by advances in information technologies. In the telecommunication sector, local loop unbundling (LLU) is an example of these new policies, developed not only to fuel competition but also, in the longer run, to facilitate and accelerate the development of broadband internet access to a large portion of countries' population.

\footnotetext{
${ }^{1}$ Public utilities are a key part of the reform package that is now often referred to as the "Washington Consensus".

${ }^{2}$ A very large literature has focused on many other sectors and policies, including the financial sector (Frieden, 1991), environmental policies (Schofer and Hironaka, 2005), corporate governance (Kester, 1996; Khannah et al., 2006), social security systems (Collier and Messick, 1975), the retail industry (Upham, 1996), antitrust policies (Dumez and Jeunemaitre, 1996) and national innovation systems (Holzinger and Knill, 2005; Lundvall and Tomlinson, 2000). These studies display a large variation in terms of how much convergence actually occurs across these sectors
} 
As illustrated by Figure 1 below, LLU is an example of a regulatory policy that has diffused progressively through countries, in a process similar to an 'S curve', which often characterises the diffusion of successful technologies (Rogers, 1962). Following the United States' leadership (in 1996, the United States became the first country to adopt the LLU decision), countries have, step by step, followed; and the idea that LLU is a necessary condition for regulatory success is now well-established everywhere. Even in countries that have not yet implemented LLU (for instance, in most countries of Asia and Latin America), this regulatory policy is being considered and discussed among politicians, regulators, incumbents and new entrants.

\section{Figure 1: The international development of LLU regulation}

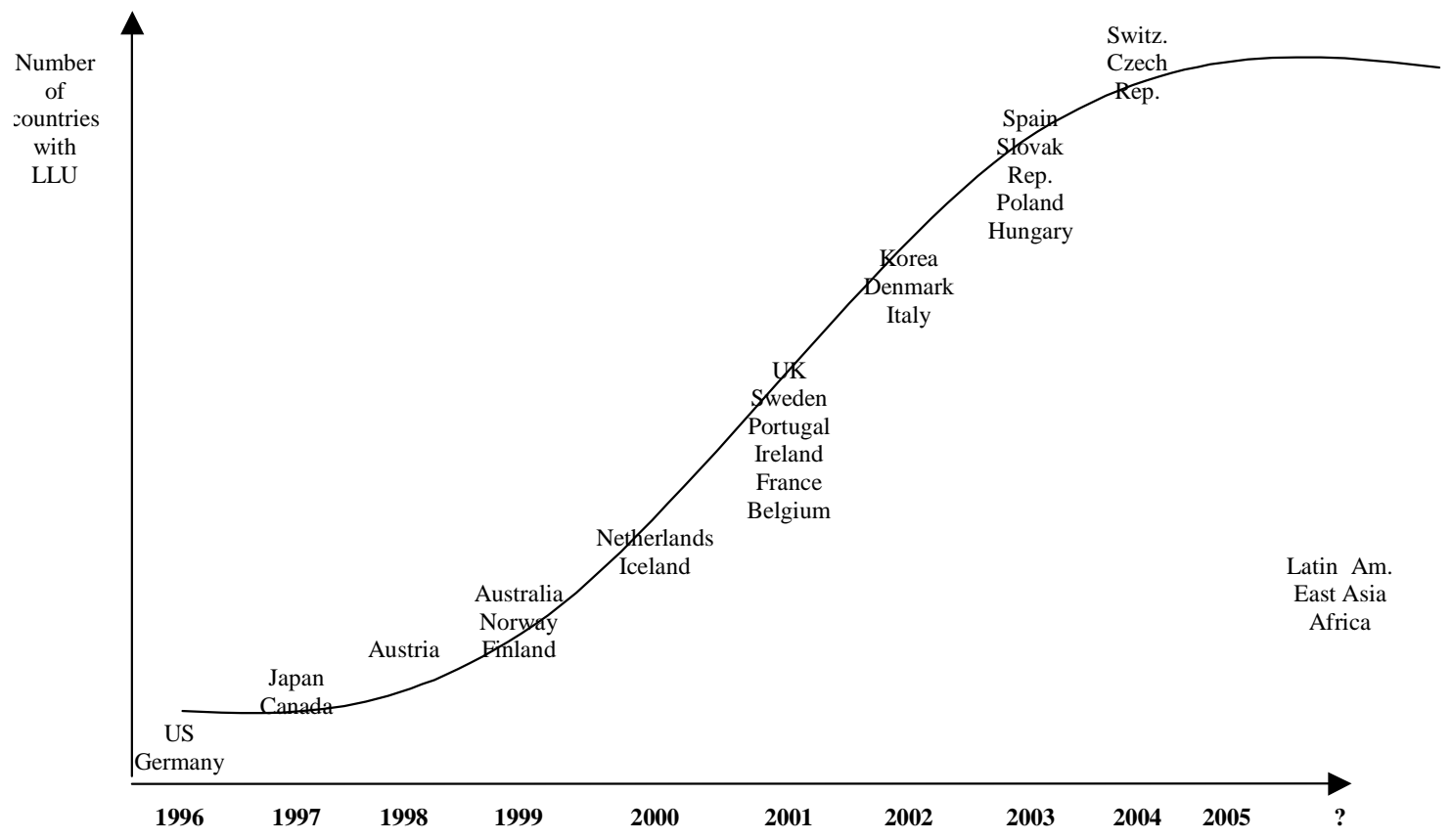

Source: Computed by authors, based on data from OECD (especially, Umino (2004))

However, the idea that LLU is an example of a best practice that has diffused through imitation and that has generated relatively uniform types of performance is not supported by further investigation.

First, in many countries, LLU has been discussed as a potential regulation but has been later dismissed. Such was the case in Chile, Switzerland and New Zealand, where LLU has been rejected or at least postponed (Paltridge, 2001). Similarly, even in countries where LLU 
regulation has been adopted, its application is carried out in many different ways. Umino (2004) provides a detailed discussion of the various forms of LLU that have appeared in different countries, including full LLU, line sharing, bitstream access or sub-loop unbundling, and the various collocation options that have also emerged (e.g., caged collocation, co-mingling, remote collocation and virtual collocation).

The regulatory obligations imposed on incumbents in the context of LLU also vary significantly across countries: in the United Kingdom, for example, the incumbent needs to fulfil clear service commitments vis-à-vis new entrants or pay fines if these commitments are not met; in Germany and Austria, on the other hand, unbundling decisions are considered only when new entrants request LLU; finally, in Australia, a process of self-regulation by the industry itself is being introduced. These observations suggest that if some convergence has appeared, it nevertheless remains quite far from pure imitation and involves a significant amount of experimentation or exploration by most countries.

This heterogeneity in the adoption of LLU is true also for the result/output of this type of regulation. As illustrated by Figure 2, the level of broadband diffusion has sharply increased during the last few years, but it remains varied even among OECD countries; other measures of the results of LLU (speed of access, for example) reveal similar heterogeneity. Finally, empirical studies that have tried to identify and isolate the impact of LLU on broadband development have been inconclusive at best (Hausman and Sidak, 2005; Wallsten, 2006).

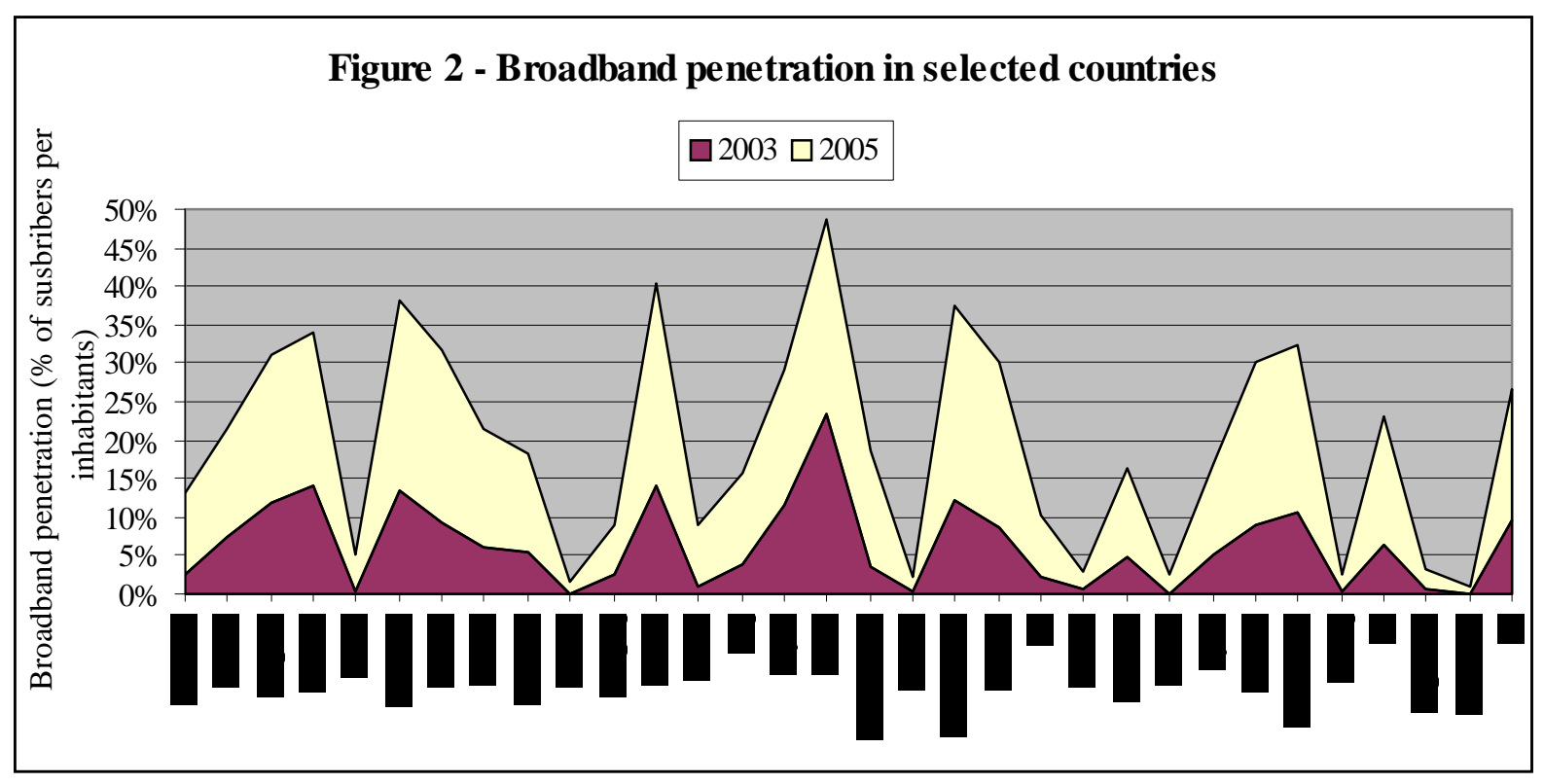


These observations are not specific to LLU but apply to many other regulatory policies implemented to reform public utilities, in which heterogeneity tends to persist in forms and results (Dimitrova and Steunenberg, 2000; Lundvall and Tomlinson, 2000; Lutz, 2004; Nicolaides, 2004; Radice, 2000; Upham, 1996).

This paper sets out to explain some aspects of this remaining heterogeneity and, more precisely, addresses the following two questions:

1. What explains this partial regulatory convergence, which includes both a dose of imitation and a fair amount of remaining heterogeneity among countries?

2. Why do some regulatory policies generate strong positive results in certain countries, but fail to do so in other countries?

As explained earlier, the canonical model of regulatory convergence is based purely on the imitation and international diffusion of best practices. However, two important aspects related to the political economy of regulatory change are missing in this model.

The first is interest group competition (Baron, 2001; Bonardi et al., 2006). Public utilities where competitive entry is feasible are characterised by heavy lobbying activities both by incumbents (including their employees, who benefit from rents if the regulatory status quo is maintained) and by new entrants (especially multinational groups trying to benefit from the assets and experience accumulated elsewhere, which tend to push regulation towards the imitation of practices that have been successful in other countries) (Bonardi, 2004; Campbell, 1994; Cawson et al., 1990; Teske, 1991; Vietor, 1994). ${ }^{3}$ When these (often) opposed influences on policy-making are taken into account, regulations tend to display features that are neither full imitations of best practices nor full rejection of them, but experiment by combining some elements of each. Experimentation with different forms of regulation can therefore emerge as a form of compromise between the preferred points of various interests that are parts of the policy-making process. Instead of considering discrete outcomes, such as pure 'local path' or pure 'imitation', we will consider the policies as a continuum as illustrated by Figure 3.

\section{Figure 3: The policy continuum}

\footnotetext{
${ }^{3}$ The important political role that multinational firms can play in the process of regulatory convergence has already been highlighted in previous work. For example, in the context of the pharmaceutical industry, Ramamurti (2006) stresses the political strategy developed by one multinational, Pfizer, which played a decisive role in pushing towards regulatory convergence.
} 


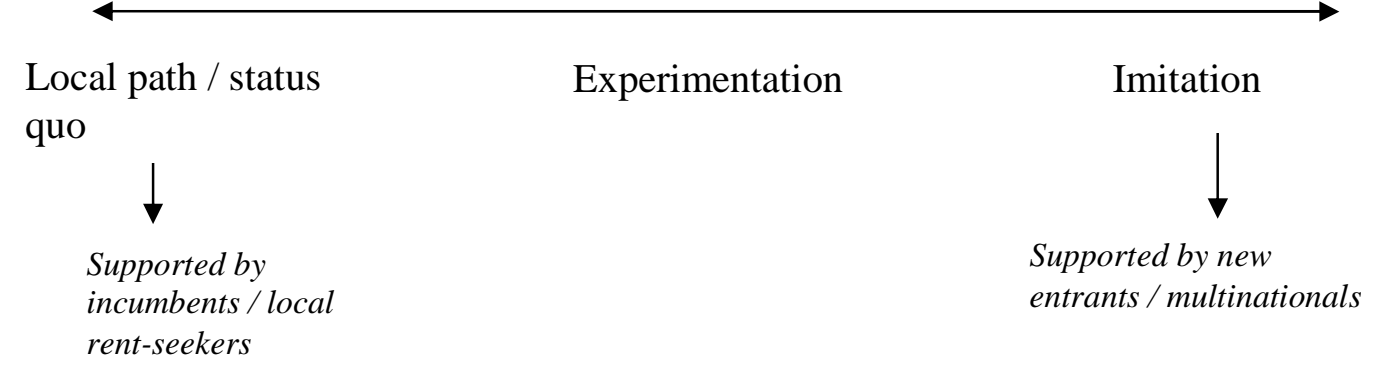

The second political economy feature that we add to our study is the importance of 'institutional fit'. As argued by North (1990) and proponents of the New Institutional Economics (NIE), policies developed successfully in certain countries might be failures in other countries because those policies don't fit with other countries' underlying institutional conditions. A country's institutional conditions and specific arrangements determine key aspects of how individuals behave with respect to each other (degree of opportunism and self-interest, for example), and therefore significantly affect transaction costs and the expected outcomes of regulatory policies (Levy and Spiller, 1994). As argued by Mukand and Rodrik (2005), if a country imitates a policy that has been successfully implemented in a very institutionally distant country, this same practice is unlikely to improve the local situations. Regulatory imitation and convergence might not improve welfare, which should be taken into account in the regulatory authority's decision. In our model, the regulatory authority will thus be influenced not only by the lobbying of incumbents and by new entrants but also by social welfare, i.e., through the reluctance to select a policy that is far from the country's underlying institutional conditions.

In what follows, we develop a simple theoretical model to capture these dimensions, derive some empirical predictions from the model and return to the case of local loop unbundling to illustrate and discuss these predictions.

\section{Regulatory decisions, lobbying and institutional fit: a model}

In our model, two interests (multinational interests or new entrants on one side; and local interests, such as incumbent operators on the other side) attempt to influence a single decisionmaker, the authority in charge of regulating the utility sector in a given country. These two interests behave as principals that seek to contract with the regulatory authority for the policy; the regulatory authority is thus a common agent of the two interests, as in Baron (2001), Bernheim and Whinston (1986) and Grossman and Helpman (1994).

\section{Competing interest groups}


The regulatory authority has to choose a policy $x \in \mathfrak{R}$. Two types of interest groups try to influence the regulatory authority's decision: multinational actors, $m$, and local actors, $l$. Multinational actors have a preference for pushing the policy decision towards the imitation of policies developed in other parts of the world where these firms have been successful, whereas local actors have a preference for keeping a regulatory status quo (the local path) from which they can obtain higher rents. ${ }^{4}$ For both types of actors, policy preferences are represented by a quadratic utility (loss) function $u_{i}(x)=-\alpha_{i}\left(x-z_{i}\right)^{2}$, with $\alpha_{i}>0$ and $i=m, l$. These actors have respective ideal points $z_{m}>0$ and $z_{l}<0$, and seek to move the policy in their preferred direction.

The two groups therefore compete in the political marketplace to influence the policy decision. This competition may take several forms, such as providing resources to the authority that are politically valuable in terms of credibility, information or financial resources. We voluntarily adopt a loose and large definition of what constitutes supports to the regulatory authority.

For instance, multinationals pushing for a standardisation of the regulatory procedures in public utility sectors can provide very valuable resources, such as helping to acquire financial support from the World Bank or the IMF (International Monetary Fund), which has been a key factor of public utility reforms in Latin American and many other countries in the 1980s to 1990s (Henisz et al., 2005). On the other hand, local interests and incumbents can provide the opposite support (in favour of the status quo) by leveraging local public opinion against the imitation of regulatory procedures developed elsewhere.

Similarly, prospective entrants are often favoured with policies that open formerly exclusive sectors granted to past service providers, either public or private, shaping the position and rentseeking activities of different player in various countries. Notice also that entrants could have a much more relevant role in those industries that technically are more suited to the development of competition, in particular the telecom sector, and to a lesser degree the energy sector (i.e., the generation of electricity and production of natural gas) and international transportation.

Formally, their support is given by the schedules $s_{i}(x), i=m, l$, with policy $x$ chosen by the regulatory authority. We further assume that these support functions are linear, in the following way: $s_{m}(x)=m \cdot\left(x-z_{l}\right)$, and $s_{l}(x)=l .\left(z_{m}-x\right)$. That is, the multinational pays $m$ per unit of

\footnotetext{
${ }^{4}$ Certainly, multinationals might prefer different policies in various countries depending on their status in each place (as entrants or incumbents). Therefore, our description of multinationals here only focuses on their demand for regulations facilitating entry in those countries where they are not the incumbent players. More generally, new entrants might not even be multinational firms.
} 
deviation from its less desired policy $\left(z_{l}\right)$ and the local interest pays $l$ per unit of deviation from $z_{m}$.

\section{The regulatory authority}

Similar to Mukand and Rodrik (2005), we start with a sector with the underlying state of the world $z$, in which a regulatory authority implements a policy $x$, therefore reaching a performance given by

$$
p_{j}(x)=-\theta(x-z)^{2}
$$

We assume that $z \in\left[z_{m}, z_{l}\right]$, i.e., that the country's underlying institutional conditions call for a policy that is between the preferred points of the competing interest groups.

With such a definition of the regulator's preferences, the closer or the more appropriate the policy to the underlying state of the world, the higher the performance of the sector. For the generality of the model, we do not specify the nature of this performance, which could include several factors, such as the level of investment in the network, the network coverage of the country, the quality of the service provided to the customers or the (lowest) overall cost of services provided. Also, while we refer to the state of nature $z$ as known (common knowledge), the fact is that players (including the regulator) have only an unbiased estimation of it. ${ }^{5}$

This performance of the sector is assumed to be a component of the regulatory authority's objective function, alongside the two interests' support schedules. In other words, the regulatory authority will balance the support it can acquire from the interests (i.e., its own private interest) with some willingness for the public utility sector to achieve its best possible performance (i.e., the public interest). We believe that this combination of private and public objectives provides a general and relatively accurate depiction of the tensions facing many regulatory agencies and bureaucracies (for a discussion, see Mueller, 2003).

The regulatory authority's preferred policy (absent any pressures) is thus assumed to be the policy that maximises the performance of the sector $p_{j}(x)$, i.e., the policy that reduces the distance between the policy chosen $x$ and the state of the world $z$. Once those pressures or supports are taken into account, the regulatory authority is assumed to have a differentiable, quasi-linear utility function given by

$U_{R}(x)=p_{j}(x)+s_{m}(x)+s_{l}(x)$.

\footnotetext{
${ }^{5}$ This incomplete information assumption is needed to avoid the fact that, if $z$ was perfectly known (common knowledge), then the regulator could be penalized for implementing $x^{*}$ different than $z$ (as this would demonstrate a bad policy choice, motivated by the support -transfers- received from any or both interest groups). Yet, to simplify the exposition, we leave it aside in what follows.
} 


\section{Sequence of play}

The interests are assumed to choose their support schedules simultaneously, anticipating the optimal reaction of the regulator to them. The game sequence is thus that the interests simultaneously offer support schedules and then the regulatory authority chooses the policy $x$.

\section{General analysis of the game}

The common agency equilibrium $\left(s_{m}^{*}(x), s_{l}^{*}(x), x^{*}\right)$ is defined as

$x^{*} \in \arg _{x} \max p_{j}(x)+s_{m}^{*}(x)+s_{l}^{*}(x)$

with

$$
s_{m}^{*}(x) \in \arg _{s_{m}(.)} \max -\alpha_{m}\left[x^{*}\left(s_{m}(.), s_{l}^{*}(.)\right)-z_{m}\right]^{2}-s_{m}\left(x^{*}\left(s_{m}(.), s_{l}^{*}(.)\right)\right)
$$

and

$$
s_{l}^{*}(x) \in \arg _{s_{l}(.)} \max -\alpha_{l}\left[x^{*}\left(s_{m} *(.), s_{l}(.)\right)-z_{l}\right]^{2}-s_{l}\left(x^{*}\left(s_{m} *(.), s_{l}(.)\right)\right)
$$

As pointed out before, we assume that the two principals decide on their support schedules first and then the agent reacts to them. Nevertheless, when the principals make their choice, each of them incorporates the regulator's reaction function, as determined by the first-order condition of its optimisation problem. Because each principal makes a punctual prediction of the support schedule offered by the other principal, but both recognise that the agent will optimally react to their aggregated support schedules, an equilibrium requires that those predictions are correct.

Providing some second-order conditions hold, an interior solution for the two support schedules falls short of a coordinated solution in which the two principals agree on the overall incentive to be provided to the agent.

\section{Equilibrium}

Thus, assuming that the support schedules are differentiable, the solution is the following.

First, from R's problem, the first-order condition yields $x^{*}=\frac{(m-l)}{2 \theta}+z$.

Second, taking into account this reaction into their own problems (i.e., replacing $x *$ into their optimisation problems), both principals decide on their support schedules (the values of $m$ and $l$ given our assumptions), according to the following two first order conditions:

$$
\begin{aligned}
& m:-\left(\alpha_{m} / \theta\right)\left[(m-l) / 2 \theta+z-z_{m}\right]-\left[(m-l) / 2 \theta+z-z_{l}\right]-m / 2 \theta=0 \\
& l:\left(\alpha_{l} / \theta\right)\left[(m-l) / 2 \theta+z-z_{l}\right]+\left[(m-l) / 2 \theta+z-z_{m}\right]-l / 2 \theta=0 .
\end{aligned}
$$


Solving these two equations to find the values of the incentives (marginal supports) $m^{*}$ and $l^{*}$ simultaneously offered to the regulator by the two interest groups, we obtain equations that are rather messy. However, the following expression, providing the difference of marginal supports by the two interests, is quite illustrative (and what is needed to solve $x^{*}$ as a function of exogenous parameters):

$$
m^{*}-l^{*}=\frac{2 \theta\left[\alpha_{l}\left(z_{l}-z\right)+\alpha_{m}\left(z_{m}-z\right)+\theta\left(z_{m}+z_{l}-2 z\right)\right]}{\left(\alpha_{l}+\alpha_{m}+3 \theta\right)} .
$$

Indeed, replacing this into the regulator's choice function, we have:

$$
x^{*}=\frac{\left[\alpha_{l}\left(z_{l}-z\right)+\alpha_{m}\left(z_{m}-z\right)+\theta\left(z_{m}+z_{l}-2 z\right)\right]}{\left(\alpha_{l}+\alpha_{m}+3 \theta\right)+z} .
$$

From the first equation, it is easy to see that if the true state of nature (as expected by everyone) is half-way between the two extreme policies supported by the interest groups (i.e., if $z=\left(z_{l}+z_{m}\right) / 2$ ), and if the two interests have the same intensity of preferences or capacity to influence the regulatory policy (i.e., if $\alpha_{l}=\alpha_{m}$ ), then $l^{*}=m^{*}$, leading to $x^{*}=z$. Indeed, in the symmetric case where the two interests have equally intensive preferences and are also equally distant from the (expected) state of nature $z$ regarding their preferred policies, the (marginal) supports offered are the same, and the policy chosen by $\mathrm{R}$ turns out to be the one that maximizes performance $p(x)$.

While other results (out of the symmetric case) are ambiguous, it is easy to verify that, when $z=\left(z_{l}+z_{m}\right) / 2, m^{*}>l^{*}$ if $\alpha_{m}>\alpha_{l}$ (that is, the most interested principal offers the highest support). More generally, $x^{*}$ increases with $z$, decreases with $\alpha_{m}$ and increases with $\alpha_{l}$. Also, $x^{*}$ moves closer to $z$ when $\theta$ increases (i.e., when the performance is more affected by the policy chosen).

Also, since the two principals cannot coordinate the level of their support schedules (so that they could minimize $s_{m}()+.s_{l}($.$) for a given net support s_{m}^{\prime}()+.s^{\prime} l($.$\left.) , or m^{*}-l^{*}\right)$, part of their utilities are captured as rents by the agent.

To make it easier to explore both the properties of this equilibrium and its relevance to our analysis of convergence, consider a more specific numerical example with parameters taking the following values: $\alpha_{m}=\alpha_{l}=\theta=1, z=0, z_{l}=-\frac{1}{4}$, and $z_{l}=-\frac{1}{4}$.

In that case, the equilibrium is $x^{*}=\frac{1}{10}$. Also, if $\alpha_{m}$ increases to 2 (all else remaining the same), then $x^{*}=\frac{1}{6}$ (a higher value, as the multinational became more interested in supporting a policy closer to its preferred point).

One can see from this solution that none of the interest achieves exactly what it wants. But because the interests know that they would be worse off if they didn't lobby, they each lobby to 
be a counterpoint to the other. As seen before, though, this does not mean that the regulatory policy adopted affects the two interests equally. In fact, the multinationals / new entrants find themselves advantaged by the regulatory outcome: they have more extreme preferences (when one considers their respective ideal points, $\left|z_{m}\right|>\left|z_{l}\right|$ ), are ready to spend more to pull the policy towards their preferred point (we do not calculate how much each interest spends here, but this can be easily done and would support this point), and therefore end up with an equilibrium for the game to their advantage, i.e. towards some forms of imitation and regulatory convergence that are closer to the policies they advocated for than to those claimed by the incumbents.

On the other hand, if the situation were reversed and $\left|z_{m}\right|<\left|z_{l}\right|$, then the equilibrium would tend to a more local solution as favoured by the incumbents / local interests.

A first general prediction emerging from this analysis is that imitation and regulatory convergence tend to become stronger in cases where (1) multinationals and/or new entrants have a stronger preference and allocate more efforts towards pulling the policy in their favour, and in cases where (2) incumbents and/or local interests have relatively less extreme preferences (Prediction 1).

Also, when the underlying institutional environment allows the enforcement of policies favouring competition and entry (i.e., $z$ is closer to $\mathrm{z}_{\mathrm{m}}$ ), then the expected policy choice is closer to imitation (Prediction 2).

A more general prediction for the study of regulatory convergence is that, as soon as the policymaking process portrays both incumbents and new entrants / multinationals, the policy outcome will be characterised by some form of experimentation (rather than a pure local solution or pure imitation). Regarding policy diffusion, one should observe direct imitation of regulations developed elsewhere (i.e., 'off the shelf') only in some very rare occasions. In most cases, even if multinational firms are influential, local aspects will be included and some local experimentation will follow (Prediction 3).

Another aspect of the equilibrium solution that we haven't discussed so far relates to the weight of the different actors in the policy-making process $\left(\alpha_{m}\right.$ and $\left.\alpha_{l}\right)$. Irrespective of the interests' preferred positions, these weightings will have a key impact in the game. ${ }^{6}$ They can also change over time if, for example, public opinion turns widely against the imitation of best practices developed elsewhere. In that case, the convergence process might even be stopped or reversed.

\footnotetext{
${ }^{6}$ As an illustration, if $\alpha_{\mathrm{m}}$ increases from 1 to 2 (and the rest of the variables remain with the same values as previously illustrated in the text), $x^{*}$ increases from $1 / 12$ to $1 / 4$ (much closer to $1 / 2-z_{m^{-}}$, the favorite policy for multinationals and new entrants).
} 
Thus, a breach in the convergence process would be characterised by a situation in which strong new entrants pushed towards imitation in an early period, whereas stronger local interests (potentially driven by a change in public opinion) regain influence and pull policy more towards a local solution (Prediction 4).

Our equilibrium solution has also important implications for policy performance in the sector, as discussed below.

\section{The question of the performance of regulatory reforms}

Our model has predictions for the equilibrium policy to be observed in each country, and this equilibrium provokes different performances according to the underlying state of nature $(z)$ characterising each country. Thus, we can think of 'institutional distance' as the differences in $z$ across countries, a variable that affects the regulatory policies adopted (leading to convergence or not) but also -more directly- the performance derived from a given policy in various countries.

Figure 4 summarises the implications of our framework on the question of regulatory reforms. Remember that policy choices here are viewed as a continuum between the pure imitation of foreign policies (as favoured by entrants and multinational actors) and a pure local solution close to the status quo (favoured by incumbents and local rent-seekers). The other important dimension is the institutional distance between the country profiled and the countries that have developed the most successful regulatory policies (i.e., the best practices that multinational actors would like to see implemented everywhere).

When institutional distance is narrow, the best performance will come from countries that have imitated their leading peers, i.e., from countries in which entrants and multinational actors have been strong enough relative to incumbents and local actors to pull regulatory policies towards the imitation of best practices (as in Prediction 1 or for countries with an institutional environment naturally leading to entry and competition (as in Prediction 2).

When institutional distance increases, imitation becomes less and less efficient because the 'offthe-shelf" policies' fit with the local institutional environment tends to worsen. Therefore, for countries that are "far from leaders" (institutionally), the most successful policies should be those that involve a higher level of experimentation and the discovery of specific institutional arrangements and regulatory policies with a better fit to the underlying local formal and informal institutions.

As per our model of the previous section, such policies take place in countries with a greater balance between multinational actors and local interests. Each type of interest tends to pull policy in its preferred direction, and the regulatory authority is better off selecting the in-between option that involves a significant amount of experimentation. 
In our model, experimentation also takes place when it should take place (indeed, if $z$ is precisely halfway between $z_{m}$ and $z_{l}$, and at the same time $\alpha_{m}=\alpha_{l}$, then $x^{*}=z$ ). Thus, we could have experimentation indicating very different things: middle-of-the-way reforms that are inconsistent and respond only to the pressure of interested principals (performance in those will be poor), and reforms that strike a good balance between instrumental best-practice and domestic institutions (producing some kind of convergence at the 'principles level,' i.e., regardless of instrumental or superficial second-order details).

As the policy choice moves towards local rent-seeking and status quo (and real experimentation tends to disappear), financial resources tend to be siphoned by incumbents and local interests, leading to poor performance. This is the case when local interests dominate the political game with little lobbying counter-actions by new entrants and international actors.

Figure 4: Institutional distance, policy choices and expected performance of regulatory reforms

Type of policy

choice

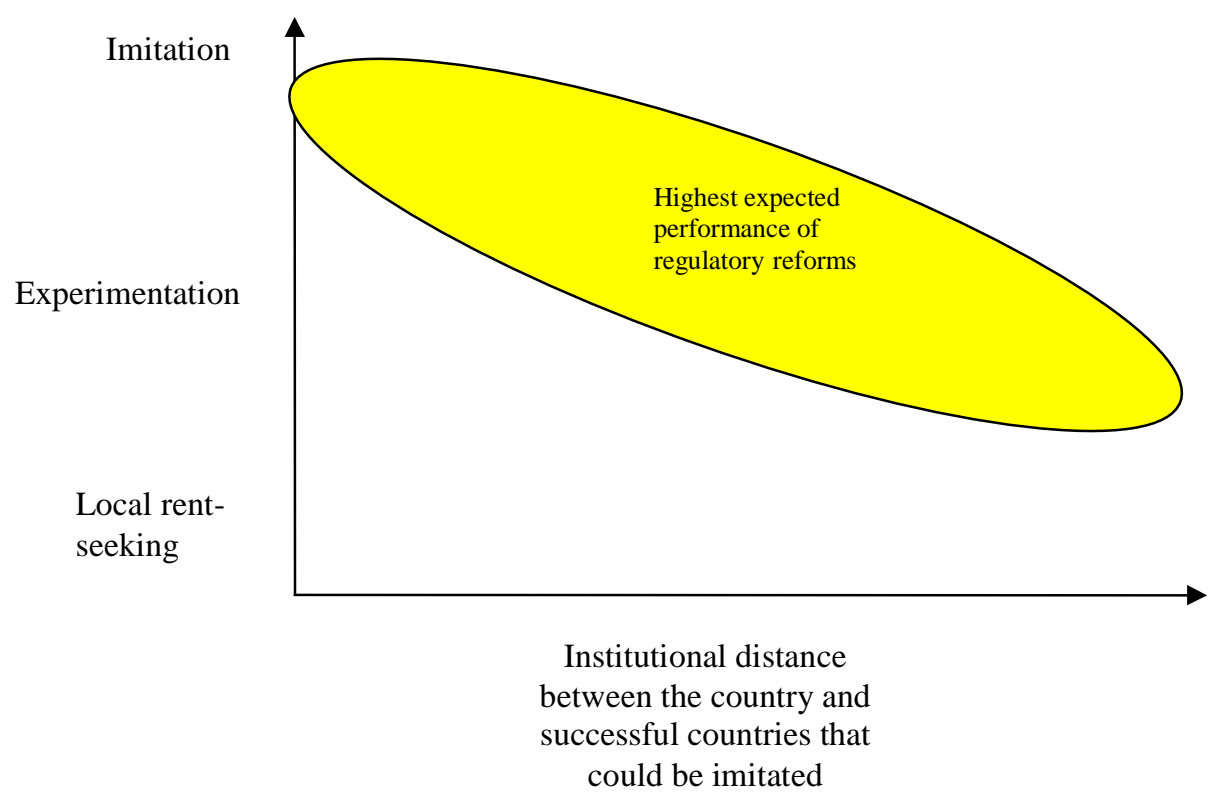

To summarise, this discussion provides the following additional predictions:

Prediction 5: For countries that are far from the leaders, those that will be the most successful with their reforms are characterised by a good mix of competition between international interests 
and local interests (experimenting with policies that combine imitation and local aspects is more likely to result in achieving regulations that fit with the underlying institutional environment).

Note that, among these countries, some will fail. However, we expect the successful countries to be those that experiment.

Prediction 6: For countries that are institutionally close to a leader (who supposedly chose a policy fitting its institutional environment), a small dose of local interest and powerful international interests will lead to more favourable outcomes, because these interests will generate a high level of imitation of existing policies that have proven to be efficient.

Prediction 7: Countries that are expected to perform poorly are countries with strong powerful international interests and/or new entrants but institutionally far from the leader, AND countries with powerful local interests and/or incumbents that could derive high benefits from imitation.

\section{The case of local loop unbundling (LLU)}

Local loop unbundling is selected for studying our predictions empirically because it has been widely presented as the best practice that regulators around the world follow to promote competition in telecommunication services. The underlying theory is that LLU makes the subscriber line available to competitors, and therefore enables the development of complementary network devices and services among a large number of competing firms (for instance, fast internet access and IP [internet protocol] telephony). Increased competition should then lead to lower access prices, better networks and higher broadband penetration. On the other hand, according to the common view, without LLU, these desired effects will not materialise.

In spite of these differing views, as argued earlier, clear variations exist regarding whether LLU has been adopted and how it has been implemented. Similarly, in terms of performance, LLU regulation is perceived as a success in some countries and a failure in many others, whereas some countries (Switzerland and New Zealand, for example) are argued to be satisfied because they haven't implemented it. The purpose of this section is to show that some of these observations can be explained by our model.

For clarity of exposition, LLU needs to be differentiated from interconnection. ${ }^{7}$ With LLU, the new entrant connects its equipment between the user and the local switch, providing the entrant with direct access to the user. With interconnection, on the other hand, the entrant is connected at a place beyond the local switch and effectively buys its access to the user from the incumbent.

\footnotetext{
${ }^{7}$ For a schematic representation of the difference between interconnection and LLU, see for instance Wallsten (2006).
} 
Interconnection thus provides a strong competitive advantage to the incumbent, who can use it to drive up the entrant's costs (especially in a system in which only the incumbent knows the real costs of the lines, making it difficult to regulate this cost externally). For this reason, LLU has been often considered a best-practice regulation, which should be implemented by most countries around the world, especially to promote the development of internet usage.

\section{Local loop unbundling and institutional fit: why LLU might not work everywhere}

In this section, we explain why LLU is expected to work well in certain countries (with certain institutional conditions) and not as well in others (especially countries that are institutionally far from these leaders).

Because our underlying assumption regarding the role of institutions is based on insights from the New Institutional Economics (NIE), it is natural to build on NIE's core concepts, especially transaction costs related to situations in which contracting is made difficult by attributes such as uncertainty, opportunism and asset specificity (Williamson, 1985). Under certain institutional conditions, LLU might create infrastructure investment disincentives and potential inefficient safeguards against transaction hazards (for a discussion, see Spiller and Ulset, 2003). Transaction cost problems, in the context of LLU, emerge because incumbents and new entrants face different sets of incentives, which can make trade and contracts between them difficult to achieve. In theory, LLU provides benefits both for incumbents and new entrants. Incumbents receive increased local traffic, and new entrants can provide complementary facilities and services. Very often, however, incumbents are worried that unbundled prices (determined by a regulatory authority) will drive profits from the increased local traffic. Two problems appear.

The first problem is related to new entrants trying to snatch subscribers from incumbents, in an industry that requires some cooperation to ensure that communications flow seamlessly through the network.

Another key problem is related to the potential costs for the new entrants, knowing that these costs will generally have to be set by the regulator. In cases in which the incumbents are strong enough to efficiently lobby for higher costs, investment incentives for new entrants disappear. In certain countries, these transaction problems might be very high, whereas in others they might be much lower because institutional rules and mechanisms will constrain the ability of incumbent to strongly influence or even bypass the regulator's decisions. Imitation of LLU regulation might therefore succeed in certain countries and fail in others depending on the underlying institutional environment. ${ }^{8}$

\footnotetext{
${ }^{8}$ The previous discussion bypasses the fact that LLU implementation could fail not just due to institutional weaknesses but also because another regulatory decision was inconsistent with the promotion of new entry in the
} 


\section{Exploring our predictions: how to measure countries' regulatory convergence in the context of}

LLU?

To explore our predictions, we first need a measure about the degree to which countries have converged regarding LLU. This is not an easy task because, as suggested earlier, countries have implemented different kinds of unbundling, making comparisons across countries difficult. To overcome this barrier, we consider a relatively simple but general data: the ratio of unbundled lines, i.e., the number of unbundled lines divided by total lines in the country.

Because we wish to capture convergence, we consider as our key measure the difference between the ratio of unbundled lines in each country and the ratio of unbundled lines for the leader, i.e., the United States. The lower this figure, the stronger the country's move towards imitation and regulatory convergence. Conversely, the higher this figure, the more the country remains close to a local path. Countries with ratios between these extremes incorporate some aspects of both and are therefore in the experimentation / discovery mode.

Figure 5 summarises these data for 32 countries in 2003.

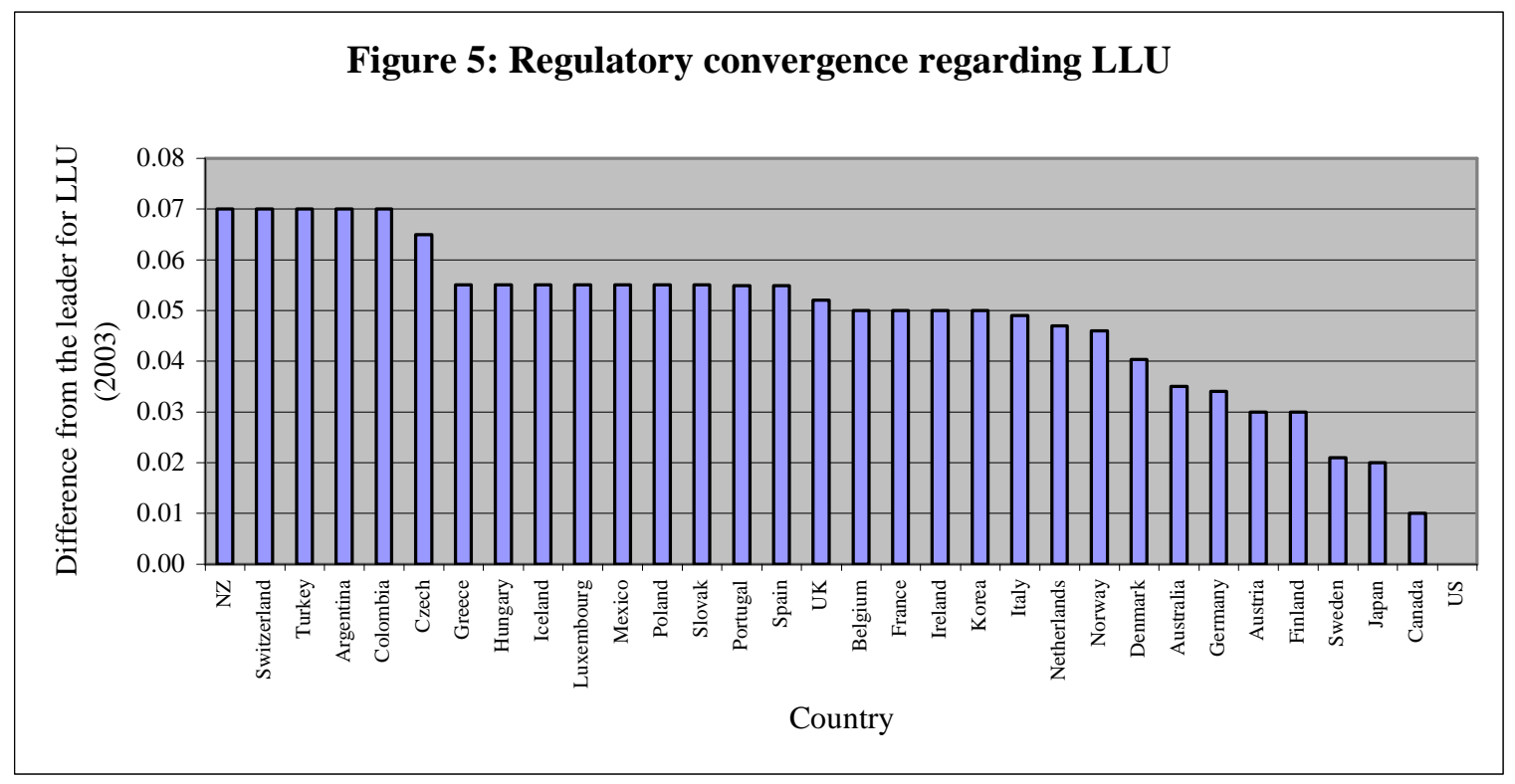

We can now use this measure to explore our predictions.

first place (e.g., minimum investment requirements and coverage obligations that are too demanding). Thus, besides institutional quality, the 'consistency' of various instrumental elements of design is key for a good performance emerging from reforms (including LLU). Under good institutional environments, one should expect a higher probability of consistency of instrumental policies, suggesting that such governance quality might be a better explanatory variable than instrumental choices, such as LLU. In any case, we don't advance on this issue here and leave this question open for further research. 


\section{Interest group competition and LLU adoption: some primary evidence}

In order to test whether insights from our model match with LLU, we need to consider two factors: (1) whether the preference / influence of incumbents matters (the assumption is that the incumbents promote a purely local path), and (2) whether the preference / influence of new entrants matters. To capture these two dimensions, we consider the following measure: the market share of incumbents in the wireless phone market (an indicator of the strength of incumbents in protecting their domestic market). ${ }^{9}$ Throughout this section, the data collected corresponds to year 2003 (which allows us to evaluate the posterior evolution of broadband penetration until 2005, based on the situation observed at that time). ${ }^{10}$

To explore our first two predictions, we plot this measure together with our measure of convergence (distance from the leader regarding LLU). Figure 6 weakly supports the influence of incumbents. The general trend is upward-sloping: the lowest level of LLU imitation tends to be found in countries where incumbents have been able to keep the highest market shares in the mobile segment (the correlation coefficient, though, is only 0.19). ${ }^{11}$

Another preliminary evaluation of our prediction 2 would be to test whether LLU adoption (as in Figure 6) is correlated with institutional quality (as reflected in the governance indicators developed by the World Bank, 2006). ${ }^{12}$ Figure 7 presents the plot, indicating that such a relationship exists: countries with better governance indicators tend to adopt LLU (and this time the correlation coefficient is more significant, i.e., -0.45 , and one can easily observe that the

\footnotetext{
${ }^{9}$ Measuring the market share of incumbents in the wireless phone market is just one of various possible indicators. Another indicator could be the market share of incumbents in the long-distance market (in particular, both of them are independent of LLU, avoiding causality circles). Furthermore, after a major change in the identity of players occurs (through privatization, for example), computing these indicators might be tricky, and the strength of local interests might also be better represented in other ways.

${ }^{10}$ Focusing on 2003 data and limiting the posterior evolution to 2005 also minimise the effects of broadband penetration through cable or wireless, particularly acute in the last few years (a development that has increasingly called into doubt whether LLU is convenient or necessary in various places where it was thought to be desirable before).

11 A significant observation explaining this low correlation coefficient is Colombia (without this country, the correlation coefficient would be around 0.42 instead of 0.19). In Colombia, despite the reduced participation of incumbent operators in the mobile market, local interests have been very strong so far (in particular, they have managed to reserve the long-distance service to three -then local- operators). Thus, alternative measures to capture the strength of incumbent operators and local interests might modify the empirical support to our Prediction 1.

${ }^{12}$ The World Bank has constructed a set of six governance indicators: voice and accountability, political stability, government effectiveness, regulatory quality, rule of law and control of corruption. Because regulatory quality might be representing instrumental choices (such as LLU), we construct an aggregate governance indicator that leaves this variable outside (the values for each country, however, do not change significantly). Each of the six indicators constructed by the World Bank combines various primary sources (polls and surveys), providing some robustness to these figures that other primary studies lack. In any case, as usual, such 'soft' and subjective indicators should be interpreted with caution (as should other apparently 'harder' data).
} 
negative correlation would be much higher by limiting the sample to countries that significantly differed from the leader regarding LLU in 2003).

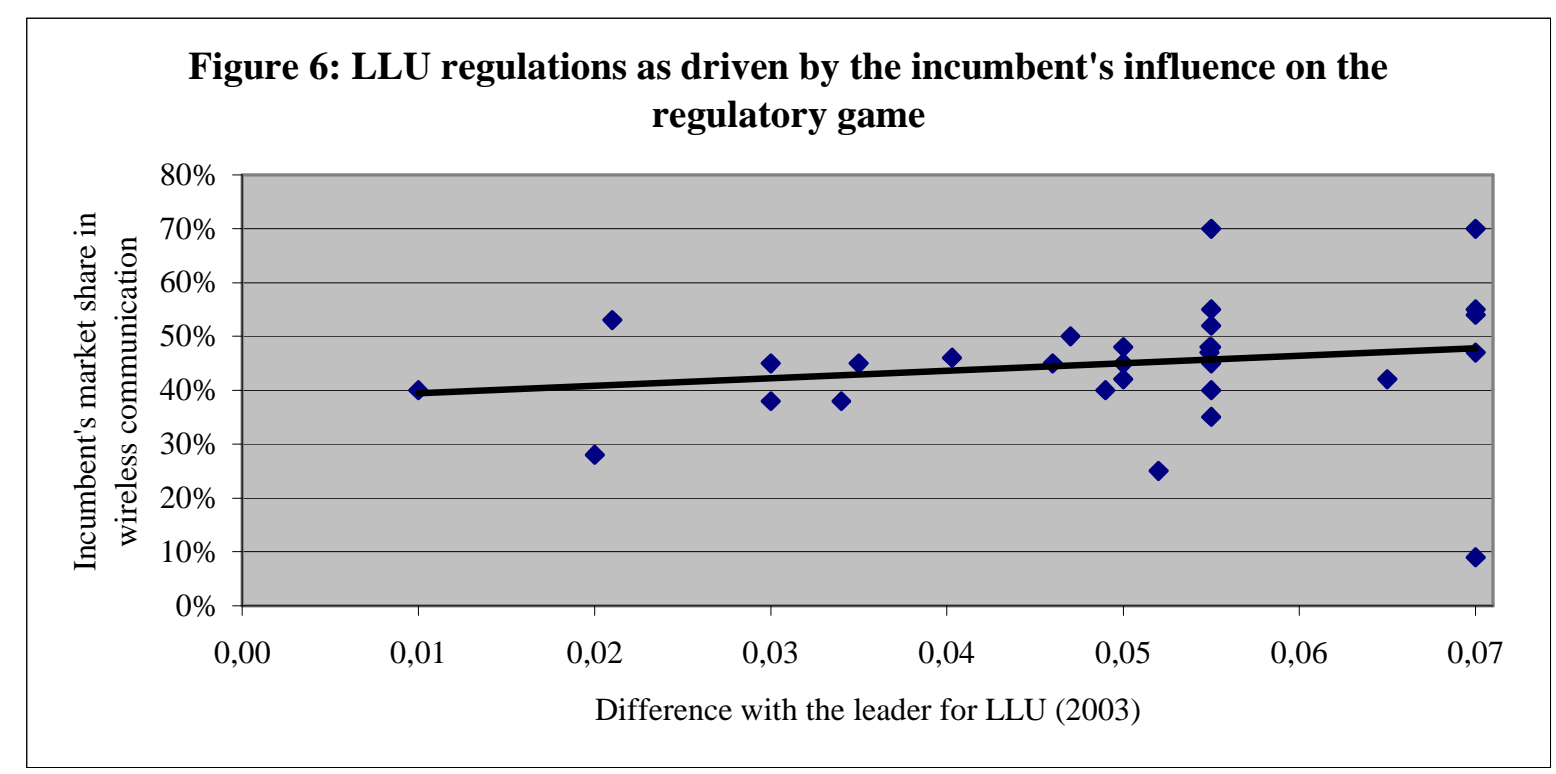

Considering these two determinants for LLU adoption, the simple linear OLS equation shown below -controlling for gross domestic product (GDP) per capita - reflects that LLU adoption as of 2003 (i.e., a smaller difference with the leader regarding LLU) is positively affected by aggregate governance and (not significantly) affected negatively by the relative importance of the incumbent in the local lobbying game (as approximated by its market share on wireless telephony):

\begin{tabular}{llcc}
$D L L U=$ & \multicolumn{4}{c}{$0.07+0.3$ Imsh -0.01 GOV -0.00 GDPpc } \\
(std. error) & $(0.02)(0.2)$ & $(0.005)$ & $(0.00)$ \\
(t-statistic) & $(3.9)(1.3)$ & $(1.8)^{*}$ & $(-0.3)$
\end{tabular}
(adjusted) $R^{2}: 0.21$, * (significant at $\left.90 \%\right)$,

where DLLU denotes the difference of LLU with respect of the leader (the United States), Imsh denotes the incumbent's market share in the wireless telephony market, $G O V$ reflects the aggregate governance indicator (average 1996 to 2003) and GDPpc denotes per capita GDP (in U.S. dollars, 2003). The low fit of the equation (21\%) clearly indicates, though, that many more determinants for LLU adoption (including those modelled before that could not be controlled here) need to be identified.

Another related and interesting question is why certain countries have decided to avoid LLU. Below we briefly look at the case study of Colombia (which bears some similarities with other 
Latin American countries) to explore whether our model retains explanatory power to explain this type of situation.

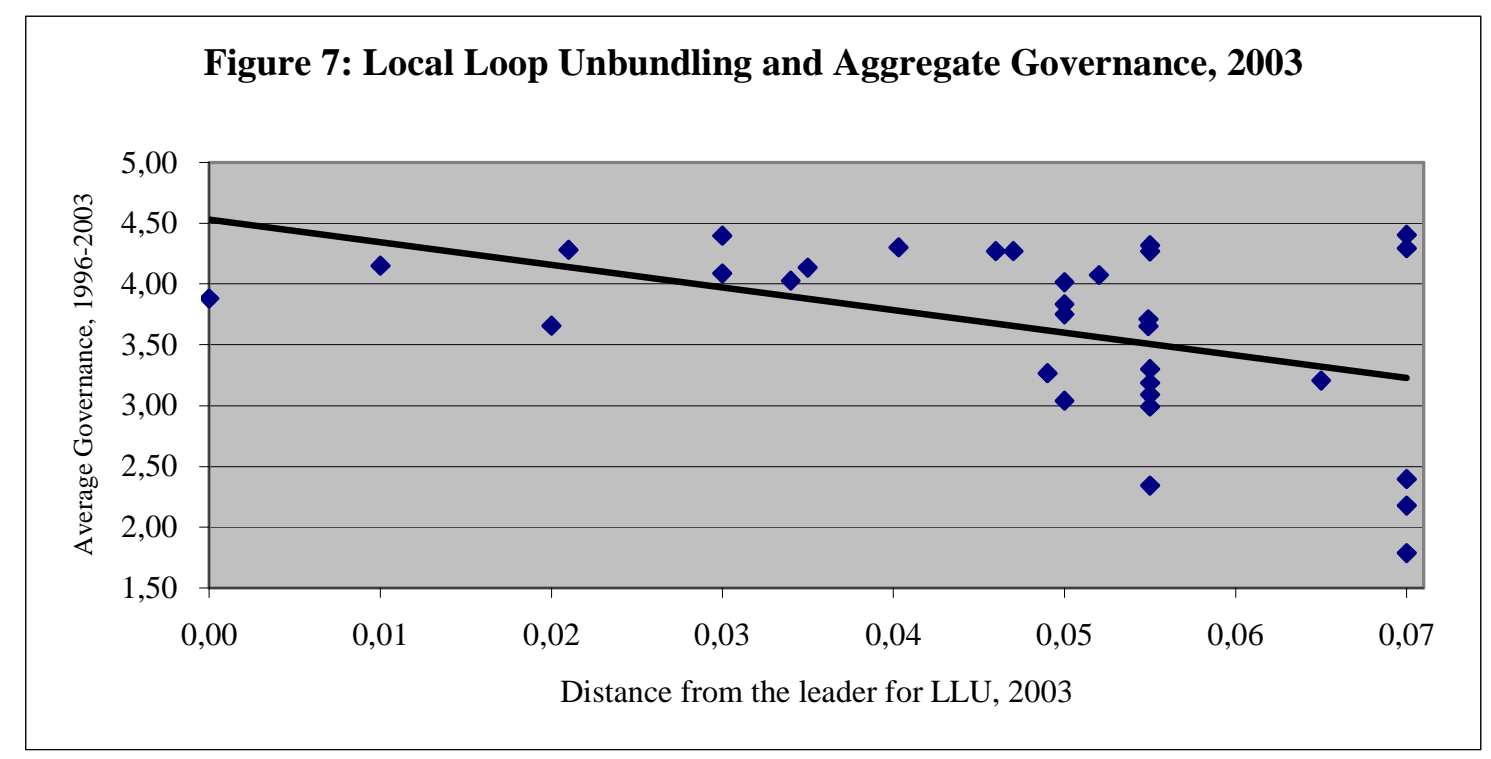

\section{Why not move towards convergence? The example of Colombia}

As with most other countries in Latin America, Colombia has chosen not to unbundle the local loop. In fact, only a timid incentive has existed to do so, provided since 2005 by article 5.2.5 in CRT (Telecommunication Regulatory Commission) Resolution 1250, by which those local operators that can prove to have sufficiently disaggregated their local loop or have received sufficient resale in their service areas, are able to ask the regulator to gain tariff flexibility vis-àvis their final users, but such flexibility is not guaranteed (nor has it been petitioned or granted so far). ${ }^{13}$ Currently, though, and due to the adaptations in its regulatory policy according to the Free Trade Agreement (FTA, or TLC by its Spanish acronyms) that is being negotiated with the United States, LLU is one of the reforms being discussed. Other reforms being considered include liberalisation of long-distance services - to be licensed under a common permit with other services, whereas now only three operators are allowed to compete - and mandatory wholesale broadband access imposed on dominant firms.

\footnotetext{
${ }^{13}$ Before this mild attempt, Resolution 087 in 1997 also stated that 'A dominant operator might be obliged to offer disaggregated network or service elements as chosen by the CRT, receiving a compensation from the requesting operator. The CRT will carry on a study about the services requiring network elements. If it finds it necessary, the CRT will ask the operators requesting LLU to present a study determining a) whether there is a potential market for the services to be offered, and b) whether the local incumbent operator is capable of providing those services at reasonable prices'. This resolution imposes a myriad of bureaucratic complications that have rendered this formal provision ineffective.
} 
As predicted by our model, this 'local-path' followed in Colombia is at least partly related to the strength of incumbents: historically, the largest operator has been Telecom, privatised to Telefónica of Spain in 2006, but other public regional operators, such as the municipalities of Medellín and Bogotá, have also been influential in the domestic political process. The influence of these incumbents - who have absorbed other minor pre-existing players - has also been strengthened by workers' unions shutting down telecom services in the early 1990s. On the other hand, the influence of international entrants, even major firms, such as Telefónica and Telmex (replacing unsuccessful initial North American investors), has remained, until recently, relatively small in comparison. As suggested in our model, a reform involving a significant level of LLU had little chance to take place in this context.

As argued by Prediction 2 in our model, the institutional environment was also not clearly conducive to entry and competition, making it less likely to push towards convergence regarding LLU. The institutional capabilities of administrating the conflicts naturally emerging between firms regarding LLU requirements have been quite limited so far: the regulatory agency (the Telecommunication Regulatory Commission, CRT) does not have control powers and has very minor sanctioning functions (reserved mostly for the Superintendence of Domestic Public Services, SSPD). The CRT's decisions - and those of other sector regulators in Colombia - are constantly challenged in the judicial system. The antitrust functions, resting within the SSPD, are also not enforced properly, given the multiple functions under its responsibility. This situation has created a significant distance between regulatory convergence regarding LLU $\left(z_{m}\right.$ in our model) and the underlying institutional environment in the country $(z)$.

\section{Institutional distance and performance: some country studies}

First, we can explore whether the 'traditional' explanation for regulatory convergence -according to which regulatory convergence flows naturally from best practices being learnt and exported everywhere- is supported by the data. If the data support the traditional view, then our model would be of little empirical relevance, at least in the case of LLU. To get a sense for the nature of regulatory convergence, we plot in Figure 8 our measure of convergence (distance with the leader) with broadband penetration. 


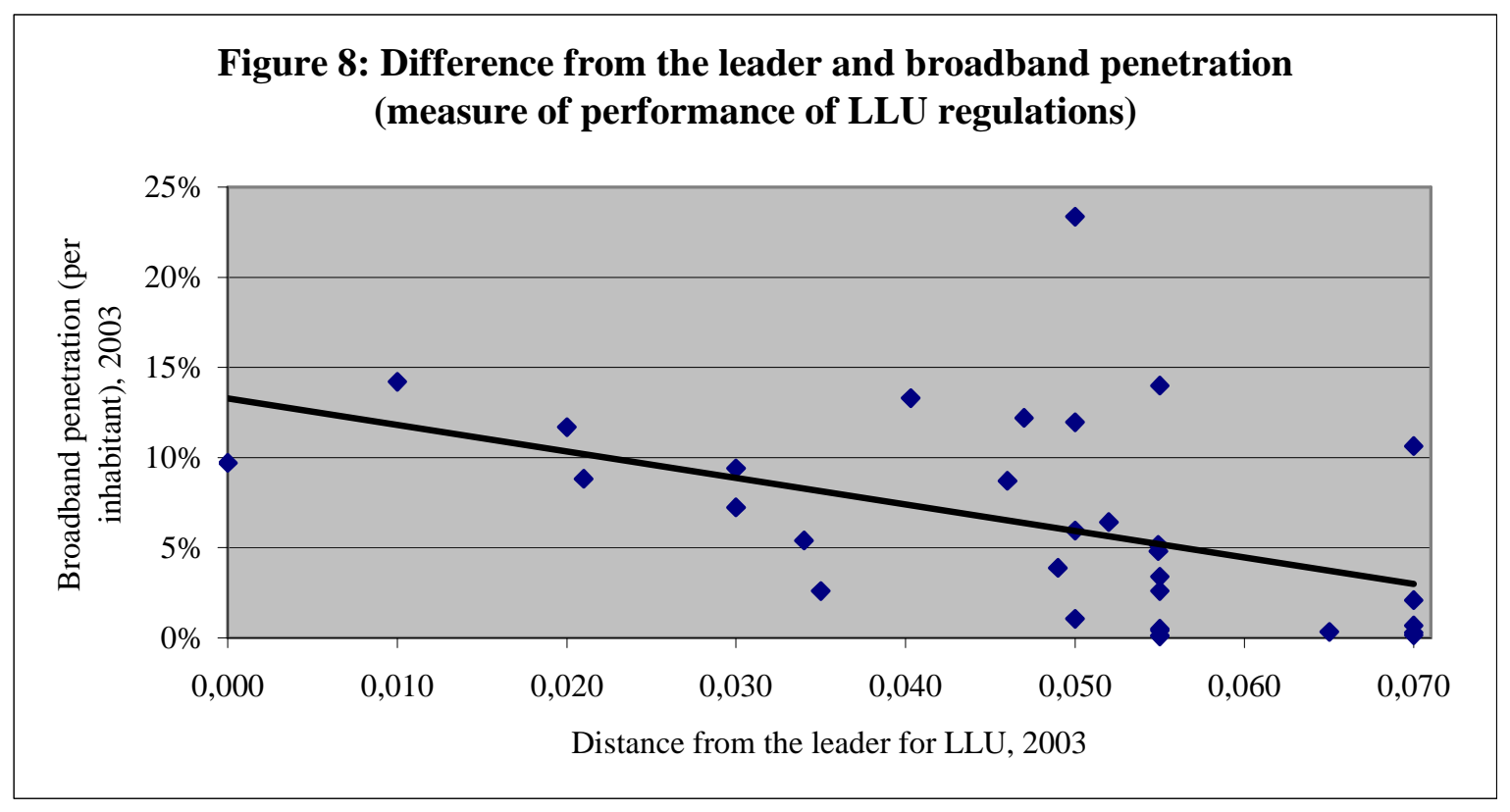

Although the data show a positive correlation between 'imitation' (small distance from the leader regarding LLU) and 'performance' (broadband penetration), such correspondence is still weak (the correlation coefficient is -0.45 , computing distance instead of proximity to the leader, as shown in Figure 8).

Also, since LLU unbundling might be related to broadband penetration resulting only from the improved use of the public telephone network, an alternative measure of performance might be broadband penetration through DSL subscriptions. In that regard, other measures of performance, such as the number of DSL subscribers per fixed line or the increase in DSL penetration between 2003 and 2005, reflect a lower correlation with LLU ( -0.33 and -0.31 , respectively). Figure 9 represents this last case. 


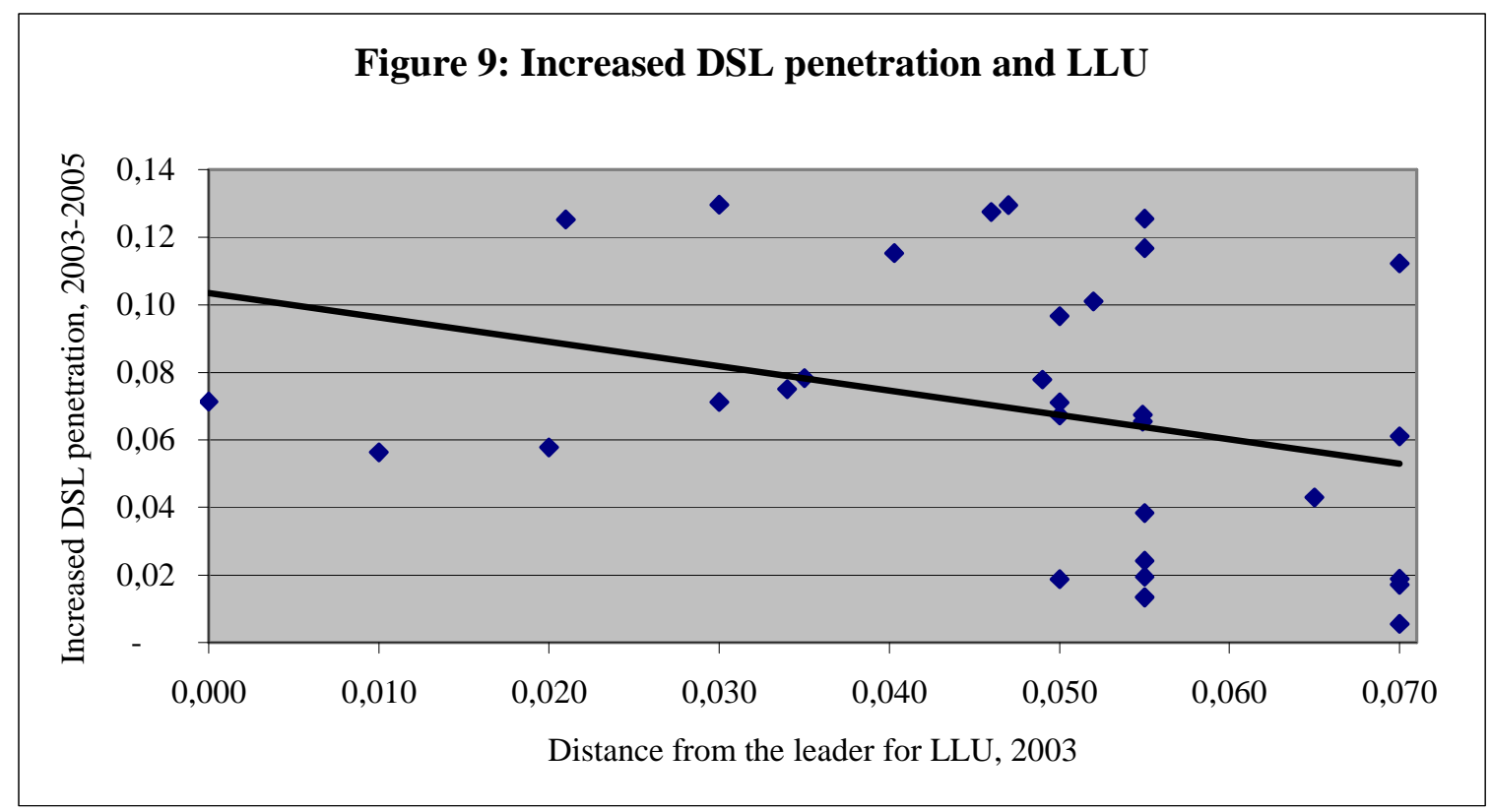

Thus, as suggested by our earlier theoretical discussion, Figures 8 and 9 bear little support for the idea that countries that have imitated LLU are the most successful ones. No obvious pattern seems to emerge.

Indeed, controlling for the number of fixed-line telephones and per capita GDP, the performance measured by increased DSL penetration between 2003 and 2005 is independent of LLU (in 2003) and is only correlated with the aggregate governance indicator for each country at that time. These results suggest that the instrumental features or details of regulation are of less importance than the overall quality of basic regulatory designs emerging from better general governance standards. More specifically, the results obtained from a simple linear regression based on the 31 observations described in the annex at the end of the paper indicate the following.

$$
\begin{array}{lccccc}
\triangle D S L= & -0.1 & +0.5 & D L L U & -0.03 \mathrm{GOV}+0.00 \mathrm{GDPpc}-0.00 \mathrm{ML} \\
\text { (std. error) } & (0.04) & (0.3) & (0.01) & (0.00) & (0.00) \\
(t \text {-statistic) } & (-2.8) & (1.6) & (2.7)^{*} & (2.0)^{* *} & (-0.01)
\end{array}
$$

(adjusted) $R^{2}: 0.62, *$ (significant at 99\%), **(significant at $\left.95 \%\right)$,

where $\triangle D S L$ denotes the increased DSL penetration (as percentage of inhabitants) between 2003 and 2005, DLLU denotes the difference of LLU with respect of the leader (the United States), GOV reflects the aggregate governance indicator (average 1996 to 2003), GDPpc denotes per capita GDP (in U.S. dollars, 2003) and $M L$ is the number of main lines per 100 inhabitants in $2003 .^{14}$

\footnotetext{
${ }^{14} G D P p c$ and $G O V$ are highly correlated (0.8), explaining why the former plays no role as an explanatory variable. If $G D P p c$ is eliminated from the OLS regression, the overall results hold (improving the significance of governance as
} 
Finally, we can see that the data used so far in the paper provides preliminary support to our Prediction 7: Figure 10 shows that DSL penetration tends to be lower in those countries having strong international / new entrant interests (as measured by the entrants' market shares in the mobile market) where, at the same time, aggregate governance is weaker (as measured by the complement of the governance index vis-à-vis its maximum possible value). ${ }^{15}$

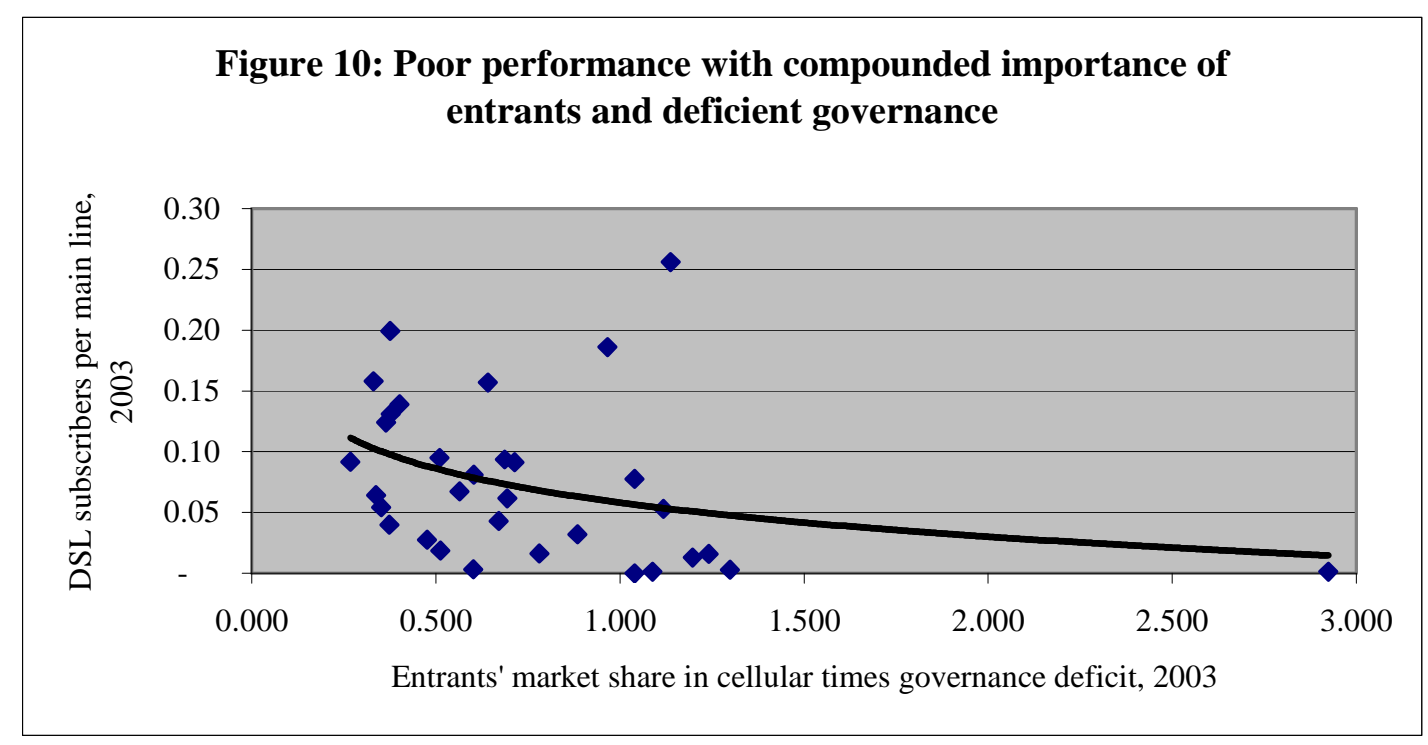

This primary analysis, based on information for year 2003, is thus consistent with the idea that "institutional fit and distance" play important roles in explaining the outcomes associated with regulatory convergence in various countries.

To explore with more qualitative details this question of the regulatory outcomes associated with LLU convergence, we now look at a couple of case studies.

\section{Austria: How an early imitator receives disappointing results because of a lack of institutional fit}

Austria was one of the first countries to imitate the LLU experience in North America. Austria allowed LLU in August 1997, i.e., in the Telecommunication Act that started the liberalisation process for telecoms in this country.

However, this liberalisation process did not lead to quick advances in the level of competition or broadband development because of long discussions between the incumbent, Telekom Austria

the only relevant explanatory variable). Still, we report this crude estimation due to its purely motivational purpose. Furthermore, computing increased broadband instead of increased DSL penetration between 2003 and 2005, the results remain qualitatively identical (with a little better fit).

${ }^{15}$ However, this result is derived from the positive correlation between performance and aggregate governance pointed out before, as broadband / DSL penetration is fully unrelated to the participation of new entrants in the mobile market. 
(TA) and potential new entrants and a lack of control of the regulatory authority over the process. The regulatory authority, newly created, was not prepared for LLU and was not in a position to impose LLU to the incumbent, therefore making the LLU ruling relatively ineffective.

Only in 1999 did the regulator clarify the rules under which firms had to operate regarding LLU. Many different agreements needed to be found not only between TA and the new entrants in telecom but also between TA and internet service providers (ISPs). This process happened slowly in 2000, 2001 and 2002. As predicted by our model, this example suggests that imitating a regulation that seems to have been successful in another country that is institutionally distant might not lead to positive results.

Finland: a country that went more for experimentation than imitation of $L L U$, but with good results because of an accommodating institutional structure

Finland is a clear example of a country that has engaged in unbundling, but through a process and with results that are radically different from those of any other OECD country. Finland's experience is as much tainted by experimentation as it is by pure imitation of the LLU as implemented in the United States and in other European countries. Much of the reason for this difference derives from the historical structure of Finnish telecommunications, which was not a monopoly but instead counted several operators, making it more prone to competition. When deregulation occurred, competition flowed naturally among these operators. LLU was mandated in 1999 and, more interestingly, granted to anybody, not only to the 'official' competitors, which already had a licence to operate.

Also, different from most other countries, telecom operators have negotiated agreements among themselves without extensive review or involvement by the regulator. Despite complaints from some new entrants, the institutional system accommodated these differences and worked quite well. Finland has one of the highest relative numbers of unbundled lines and a high broadband penetration. This example supports the idea that, in many cases, countries that experience and adapt a regulation to the local environment might be more successful than just pure imitation.

\section{Conclusion}

Should we expect to see regulatory convergence for public utilities? And, if some convergence does occur, should we expect it to be effective? This paper suggests that, on the one hand, after important political economy factors are taken into account, one should expect some convergence, but far from total convergence and still with a significant amount of local experimentation; on the other hand, this process will lead to dramatically different results regarding regulatory outcomes, 
depending on the institutional distance between the leading countries and the followers trying to mimic them.

The case of local loop unbundling seems to support these propositions. However, one needs to bear in mind some potential limitations of this case. First, LLU is still in its early stages of development (even in the United States and in Western Europe, the percentage of unbundled lines remains relatively modest; the same can be said for broadband penetration, one potential measure for regulatory success). Because of this limited time span, the convergence trajectory and regulatory outcomes related to imitation are a little more difficult to evaluate. Second, even in the United States (considered in our analysis as the leading country), LLU is still not judged as a total success. Again, the future will tell us more. Third, as preliminarily shown in the previous section, performance might be related to basic indicators of institutional quality / governance, which are the elements necessary for coherent implementation of regulatory reforms that look for more rapid and less expensive development of key telecom services and infrastructure.

The direct implication of these last two comments is that more empirical studies about regulatory convergence in public utilities and its outcome are warranted. We leave this for future research. 


\section{References}

Baron, D.P. (2001) 'Theories of strategic nonmarket participation: majority-rule and executive institutions', Journal of Economics and Management Strategy, Vol. 10, No. 1, pp.46-89.

Bennett, C. (1991) 'What is policy convergence and what causes it?', British Journal of Political Science, Vol. 21, No. 2, pp.215-233.

Berger, S. and Dore, R. (1996) National Diversity and Global Capitalism, Cornell University Press, Ithaca, NY.

Bernheim B. and Whinston, M. 1986. Menu auctions, resource allocation and economic influence. Quarterly Journal of Economics. 101: 1-31.

Bonardi, J.P., Holburn, G., VandenBergh, R. 2006. Nonmarket performance: Evidence from U.S. electric utilities. Academy of Management Journal. December, p.1209-1228.

Bonardi, J.P. 2004. Political and international strategies of former telecom monopolies: The asymmetric behaviors of former monopolies. Strategic Management Journal. February. 25, 2, p.101-120.

Campbell, J. 1994. Couriers and the European postal monopolies. In Pedler, R. and Van Schendelen, M., Lobbying the European Union, Darthmouth Publishing: Brookfield, Vermont: p.123-148.

Cawson, A., Morgan, K., Webber, D., Holmes, P., Stevens, A. 1990. Hostile Brothers: Competition and Closure in the European Electronics Industry, Clarendon Press: Oxford.

Collier, D. and Messick, R. (1975) 'Prerequisites versus diffusion: testing alternative explanations of social security adoption', American Political Science Review, Vol. 69, No. 4, pp.1299-1315.

Dimitrova, A. and Steunenberg, B. 2000. 'The search for convergence in the European Union: an impossible quest?', European Union Politics, Vol. 1, No. 2, pp.201-226.

Dumez and Jeunemaitre, 1996. The convergence of competition policies in Europe: Internal dynamics and external imposition. In Berger, S. and R. Dore, National Diversity and Global Capitalism.

Eising, R. (2002) 'Policy learning in embedded negotiations: explaining EU electricity liberalization', International Organization, Vol. 56, No. 1, pp.85-120.

Frieden, J. (1991) 'Invested interests: the politics of national economic policies in a world of global finance', International Organization, Vol. 45, No. 4, pp.425-451.

Genoud, C. and Finger, M. (2002) 'Regulatory convergence? The example of the European electricity sector', working paper, IDHEAP (Swiss Graduate School of Public Administration), Chavannes-près-Renens, Switzerland.

Gertler, M. (2001) 'Best practice? Geography, learning, and the institutional limits to strong convergence', Journal of Economic Geography, Vol. 1. No. 1 pp.5-26.

Grossman, G. and Helpman, E. 1994. Protection for sale. American Economic Review. 84: 83350 . 
Hausman, J. and Sidak, G. (2005) 'Did mandatory unbundling achieve its purpose? Empirical evidence from five countries', Journal of Competition Law and Economics, Vol. 1, No. 1, pp.173-245.

Henisz, W., Zelner, B. and Guillen, M. 2005. 'International coercion, emulation and policy diffusion: market-oriented infrastructure reforms 1977-1999', American Journal of Sociology.

Hills, J. and Michalis, M. (2000) 'Restructuring regulation: technological convergence and European telecommunications and broadcasting markets', Review of International Political Economy, Vol. 7, No. 3, pp.434-464.

Holzinger, K. and Knill, C. (2005) 'Causes and conditions of cross-national policy convergence', Journal of European Public Policy, Vol. 12, No. 5, pp.775-796.

IDATE (2006) Telecoms in Europe: Databases, Indicators and Benchmark, Montpellier, France.

ITU (International Telecommunication Union) (2006) ITU World Telecommunication Indicators 2006, ITU, Geneva, Switzerland.

Kester, W. 1996. American and Japanese corporate governance: Convergence to best practice? In Berger, S. and R. Dore, National Diversity and Global Capitalism: 107-137.

Khanna, T., Kogan, J. and Palepu, K. (2006) 'Globalization and similarities in corporate governance: a cross-country analysis', Review of Economics and Statistics, Vol. 88, No. 1, pp.69-90.

Levy D. and Spiller, P. 1994. The institutional foundations of regulatory commitment: A comparative analysis of telecommunications regulation. Journal of Law, Economics and Organization, 10: 201-246.

Lundvall, B.-A. and Tomlinson, M. (2000) 'On the Convergence and Divergence of National Systems of Innovation', Draft of contribution to special issue of Research Policy on Innovation Systems, available at http://www.business.aau.dk/ike/upcoming/Lundvall-NSI.pdf.

Lutz, S. 2004. 'Convergence within national diversity: the regulatory state in finance', Journal of Public Policy, Vol. 24, No. 2, pp.169-197.

Mueller, D. 2003. Public Choice III. Cambridge University Press.

Mukand, S. and Rodrik, D. (2005) 'In search of the Holy Grail: policy convergence, experimentation, and economic performance', American Economic Review, Vol. 95, No. 1, pp.374-383.

Nicolaides, P. (2004) 'The political economy of multi-tiered regulation in Europe', Journal of Common Market Studies, Vol. 42, No. 3, pp.599-618.

North, D. (1990) Institutions, Institutional Change and Economic Performance, Cambridge University Press, Cambridge, UK.

Paltridge, S. (2001) The Development of Broadband Access in OECD countries, OECD, Directorate for Science, Technology and Industry, Paris, France.

Radice, H. (2000) 'Globalization and national capitalisms: theorizing convergence and differentiation', Review of International Political Economy, Vol. 7, No. 4, pp.719-742. 
Ramamurti, R. (2006) 'Global regulatory convergence: the case of intellectual property rights', in Grosse, R. (Ed.), International Business and Government Relations in the $21^{\text {st }}$ Century, Cambridge University Press, Cambridge, UK, pp.341-360.

Rogers, E. (1962). Diffusion of innovations. New York: Free Press.

Schofer, Hironaka. 2005. The effect of world society on environmental protection. Outcomes. Social Forces. Vol. 84, No 1, pp.25-47.

Spiller, P. and Ulset, S. (2003) 'Why local loop unbundling fails?', Working paper, Haas School of Business, University of California, Berkeley, Berkeley, CA.

Teske, P. 1991. Rent-seeking in the Deregulatory Environment: State Telecommunications. Public Choice. 68, 1: 235-243.

Umino, A. (2004) 'Development in local loop unbundling', OECD, Directorate for Science, Technology and Industry, Paris, France.

Upham, F. (1996). Retail convergence: The structural impediments initiative and the regulation of the Japanese retail industry. In Berger, S. and R. Dore, National Diversity and Global Capitalism: 263-297.

Vietor, R. 1994. Contrived Competition: Regulation and Deregulation in America. The Belknap Press of Harvard University Press.

Wallsten, S. (2006) 'Broadband and unbundling regulations in OECD countries', Working paper 06-16, AEI-Brookings Joint Center for Regulatory Studies, Washington, DC.

World Bank (2006) Governance Matters 2006: Worldwide Governance Indicators, World Bank, Washington, DC. 
Annex: Data

\begin{tabular}{|c|c|c|c|c|c|c|c|c|c|}
\hline & $\begin{array}{l}\text { Broadband per } \\
\text { inhabitant, } 2003\end{array}$ & $\begin{array}{l}\text { Broadband per } \\
\text { inhabitant, } 2005\end{array}$ & $\begin{array}{c}\text { DSL as per } \\
\text { inhabitant, } 2003\end{array}$ & $\begin{array}{c}\text { DSL per } \\
\text { inhabitant, } 2005\end{array}$ & $\begin{array}{c}\text { Difference } \\
\text { from leader } \\
\text { regarding LLU, } \\
2003\end{array}$ & \begin{tabular}{|} 
Market share \\
incumbent in \\
wireless telephony, \\
2003
\end{tabular} & $\begin{array}{c}\text { Aggregate } \\
\text { Governance (0-5 } \\
\text { range), 1996-2003* }\end{array}$ & $\begin{array}{l}\text { GDP per capita } \\
\text { (USD), } 2003\end{array}$ & $\begin{array}{c}\text { Main telephone } \\
\text { lines (fixed } \\
\text { lines) per } 100 \\
\text { inhabitants, } 2003\end{array}$ \\
\hline Australia & 0,03 & 0,10 & 0,01 & 0,08 & 0,035 & 0,45 & 4,14 & 26.331 & 52,6 \\
\hline Austria & 0,07 & 0,14 & 0,03 & 0,08 & 0,030 & 0,38 & 4,09 & 31.208 & 47,6 \\
\hline Belgium & 0,12 & 0,19 & 0,07 & 0,12 & 0,050 & 0,45 & 3,83 & 29.677 & 46,9 \\
\hline Canada & 0,14 & 0,20 & 0,06 & 0,09 & 0,010 & 0,40 & 4,15 & 27.305 & 64,9 \\
\hline Czech & 0,00 & 0,05 & - & 0,02 & 0,065 & 0,42 & 3,21 & 8.955 & 35,5 \\
\hline Denmark & 0,13 & 0,25 & 0,09 & 0,15 & 0,040 & 0,46 & 4,30 & 39.616 & 67,0 \\
\hline Finland & 0,09 & 0,22 & 0,08 & 0,19 & 0,030 & 0,45 & 4,40 & 31.420 & 49,2 \\
\hline France & 0,06 & 0,16 & 0,05 & 0,15 & 0,050 & 0,45 & 3,75 & 29.915 & 56,6 \\
\hline Germany & 0,05 & 0,13 & 0,05 & 0,13 & 0,034 & 0,38 & 4,03 & 29.427 & 65,7 \\
\hline Greece & 0,00 & 0,01 & 0,00 & 0,01 & 0,055 & 0,40 & 3,19 & 15.254 & 55,0 \\
\hline Hungary & 0,03 & 0,06 & 0,01 & 0,04 & 0,055 & 0,48 & 3,30 & 8.219 & 35,6 \\
\hline Iceland & 0,14 & 0,27 & 0,13 & 0,26 & 0,055 & 0,45 & 4,32 & 37.343 & 66,6 \\
\hline Ireland & 0,01 & 0,08 & 0,01 & 0,06 & 0,050 & 0,48 & 4,01 & 30.936 & 49,1 \\
\hline Italy & 0,04 & 0,12 & 0,04 & 0,11 & 0,049 & 0,40 & 3,27 & 25.919 & 45,9 \\
\hline Japan & 0,12 & 0,17 & 0,09 & 0,11 & 0,020 & 0,28 & 3,66 & 33.156 & 47,2 \\
\hline Korea & 0,23 & 0,25 & 0,13 & 0,14 & 0,050 & 0,42 & 3,04 & 12.710 & 52,5 \\
\hline Luxembourg & 0,03 & 0,15 & 0,03 & 0,14 & 0,055 & 0,52 & 4,27 & 63.723 & 54,3 \\
\hline Mexico & 0,00 & 0,02 & 0,00 & 0,01 & 0,055 & 0,55 & 2,34 & 6.255 & 16,0 \\
\hline Netherlands & 0,12 & 0,25 & 0,06 & 0,15 & 0,047 & 0,50 & 4,27 & 32.866 & 48,2 \\
\hline Norway & 0,09 & 0,21 & 0,07 & 0,17 & 0,046 & 0,45 & 4,27 & 48.673 & 48,9 \\
\hline $\mathrm{NZ}$ & 0,02 & 0,08 & 0,02 & 0,07 & 0,070 & 0,47 & 4,30 & 20.435 & 45,6 \\
\hline Poland & 0,01 & 0,02 & 0,01 & 0,02 & 0,055 & 0,35 & 3,09 & 5.610 & 31,9 \\
\hline Portugal & 0,05 & 0,12 & 0,02 & 0,07 & 0,055 & 0,48 & 3,71 & 14.751 & 40,9 \\
\hline Slovak & 0,00 & 0,03 & 0,00 & 0,02 & 0,055 & 0,70 & 2,99 & 6.072 & 24,1 \\
\hline Spain & 0,05 & 0,12 & 0,04 & 0,09 & 0,055 & 0,47 & 3,65 & 20.596 & 41,6 \\
\hline Sweden & 0,09 & 0,21 & 0,05 & 0,13 & 0,021 & 0,53 & 4,28 & 33.586 & 72,9 \\
\hline Switzerland & 0,11 & 0,22 & 0,07 & 0,15 & 0,070 & 0,55 & 4,41 & 43.713 & 72,3 \\
\hline Turkey & 0,00 & 0,02 & 0,00 & 0,02 & 0,070 & 0,54 & 2,18 & 3.366 & 26,5 \\
\hline UK & 0,06 & 0,17 & 0,04 & 0,12 & 0,052 & 0,25 & 4,08 & 3.039 & 58,1 \\
\hline Argentina & 0,01 & 0,02 & 0,00 & 0,02 & 0,070 & 0,70 & 2,40 & 3.423 & 22,7 \\
\hline Colombia & 0,00 & 0,01 & 0,00 & 0,00 & 0,070 & 0,09 & 1,79 & 1.814 & 17,9 \\
\hline US & 0,10 & 0,17 & 0,03 & 0,07 & 0,000 & n.a. & 3,88 & 37.691 & 62,9 \\
\hline
\end{tabular}

Source: ITU (2006), OECD and Idate (2006).

* Based on the linear average of five indicators (voice and accountability; political stability; government effectiveness; rule of law and control of corruption), which represent the linear average of five observations between years 1996 and 2003, as constructed by the World Bank. 
